\title{
Early effect on intragastric pH of oral administration of rabeprazole with mosapride compared with rabeprazole alone
}

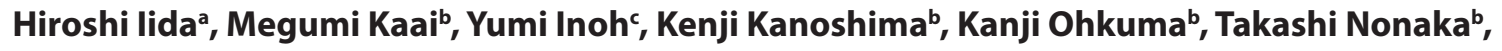 \\ Koji Fujitac, Tomonori Ida ${ }^{a}$, Akihiko Kusakabec, Shin Maedac, Atsushi Nakajimab ${ }^{b}$ Masahiko Inamoria \\ Yokohama City University School of Medicine, Yokohama, Japan
}

Abstract

\section{Introduction}

Recently, the number of Japanese patients with gastroesophageal reflex disease (GERD) has been increasing, because of changes in eating habits and a decrease in infections with Helicobacter pylori (H. pylori). Heartburn is a common problem in Japan and it interferes with daily life. Proton pump

Departments of ${ }^{a}$ Medical Education (Hiroshi Iida, Tomonori Ida,

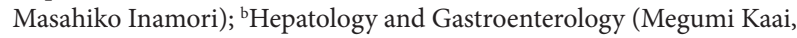
Kenji Kanoshima, Kanji Ohkuma, Takashi Nonaka, Atsushi Nakajima); 'Office of Postgraduate Medical Education (Yumi Inoh, Koji Fujita, Akihiko Kusakabe, Shin Maeda), Yokohama City University School of Medicine, Yokohama, Japan

\section{Conflict of Interest: None}

Correspondence to: Koji Fujita, Office of Postgraduate Medical Education, Yokohama City University Hospital, 3-9 Fukuura, Kanazawa-ku, Yokohama, Japan, Tel.: +81 45787 2640, Fax: +81 45 784 3546, e-mail: kfujita@yokohama-cu.ac.jp

Received 25 August 2016; accepted 13 March 2017; published online 19 May 2017

DOI: https://doi.org/10.20524/aog.2017.0161 inhibitors (PPIs) are usually used globally for the treatment of acid related diseases such as gastric and duodenal ulcers, and GERD, and as a component of eradication therapy for H. pylori [1-4]. Most GERD patients are controlled with standard PPIs, but about $10-40 \%$ of patients continue to have heartburn [5].

On-demand therapy for GERD patients is cost-effective and safe, in the form of one-dose PPIs taken when symptoms occurs [6,7]. An ideal medication for GERD patients should have the ability to act rapidly and achieve efficient symptom resolution. Multiple medicines, including antacids, PPIs, histamine 2 receptor antagonists (H2RAs), and mosapride citrate (mosapride) are currently used for GERD patients [8]. We showed previously that the oral administration of H2RA with mosapride increased the intragastric $\mathrm{pH}$ more rapidly than H2RA alone [9]. In addition, our previous study showed that omeprazole orally administered $1 \mathrm{~h}$ after mosapride increased the intragastric $\mathrm{pH}$ more rapidly than omeprazole alone [10]. However, no crossover comparisons have been reported of the acid-suppressive effect of oral PPI with mosapride versus PPI alone. We chose rabeprazole and mosapride, because we usually use these drugs for GERD patients in Japan. The dosage in this study was within the usual range in Japan. We designed this 
three-way crossover study to compare the acute efficacies of rabeprazole alone, rabeprazole with mosapride, and rabeprazole administered $1 \mathrm{~h}$ after mosapride on intragastric $\mathrm{pH}$.

\section{Patients and methods}

\section{Subjects}

Twelve male, $H$. pylori-negative volunteers participated in this randomized, three-way crossover study. Their mean age was 23.2 years (range 20-35 years) and they were not using acid suppressive medications, PPIs, and/or H2RAs, and/or mosapride. All volunteers were negative for anti-H. pylori immunoglobulin $\mathrm{G}$ antibodies according to an E plate EIKEN H. pylori antibody test (Eikenkagaku Inc., Tochigi, Japan).

\section{Study protocol and pH-metry}

All volunteers followed three oral medication protocols, as follows: rabeprazole (20 mg; Pariet ${ }^{\oplus}$, Eisai Co. Ltd., Tokyo, Japan), rabeprazole with mosapride (5 mg; Gasmotin ${ }^{\odot}$, Dainippon Sumitomo Pharmaceutical Co. Ltd., Osaka, Japan), or rabeprazole administered $1 \mathrm{~h}$ after mosapride. After each administration, we monitored their intragastric $\mathrm{pH}$ constantly for $6 \mathrm{~h}$. A washout period of at least 7 days was allowed between successive administrations. The volunteers fasted overnight (at least $8 \mathrm{~h}$ ) before the administration of medicine or medicines, and for $6 \mathrm{~h}$ after their administration; each protocol was performed in the morning.

Intragastric $\mathrm{pH}$ was measured using a portable $\mathrm{pH}$ meter connected to an antimony $\mathrm{pH}$ electrode (Chemical Instrument Co. Ltd., Tokyo, Japan). Under local anesthesia, the $\mathrm{pH}$ electrode was inserted transnasally and positioned in the upper part of the gastric body. Measurements were made at 10 -sec intervals. Before each protocol, we calibrated the $\mathrm{pH}$ electrode using standard buffer solutions at $\mathrm{pH} 4.01$ and 6.86. We analyzed the $\mathrm{pH}$ data using commercially available software (Chemical Instrument Co. Ltd., Tokyo, Japan). During the $6 \mathrm{~h}$ after the administration of each medicine, we measured the intragastric median $\mathrm{pH}$, as well as the percentages of time with intragastric $\mathrm{pH}$ above 2, 3, 3.5, 4, 5, 6, and 7 .

\section{CYP2C19 genotyping and status}

DNA was obtained from each volunteer's white blood cells. Genotyping, using the polymerase chain reaction-restriction fragment length polymorphism method, was performed at the laboratories of SRL Inc. (Tokyo, Japan) to identify the wildtype CYP2C19 and two point-mutated alleles; the wild-type allele has a $G$ at position 636 in exon 4 and a $G$ at position 689 in exon 5 [11]. One of the mutated alleles ( $\mathrm{m} 1$ allele) has an $\mathrm{A}$ at position 689 in exon 5, and the other mutated allele (m2 allele) has an A at position 636 in exon $4[12,13]$.
The prevalence of the CYP2C19 genotype varies among different races. The prevalence of CYP2C19 EM is $27-35 \%$ in Japanese, 56-69\% in Caucasians, $81 \%$ in African-Americans, $38 \%$ in Chinese and $13 \%$ in Koreans [11].

\section{Statistical analysis}

Wilcoxon's signed-rank test was used as appropriate for statistical analysis. All $\mathrm{P}$-values were two-sided; $\mathrm{P}<0.05$ was taken to indicate statistical significance. We performed all statistical analyses using StatView (SAS Institute, Cary, NC, USA).

\section{Ethics}

Approval for this study was given in advance by the Ethics Committee of Yokohama City University School of Medicine. This study was conducted in accordance with the Declaration of Helsinki. Written informed consent to participation was obtained from all volunteers before the start of this study. We registered this study protocol at the UMIN Clinical Trials Registry (UMIN-CTR; ID=UMIN000002082).

\section{Results}

All volunteers completed this study and there were no adverse events.

\section{Intragastric pH and holding times (\%) of various pH levels}

The median 6-h intragastric $\mathrm{pH}$ following the administration of rabeprazole $1 \mathrm{~h}$ after mosapride was $4.41 \pm 1.22$ (mean \pm s.d.), significantly higher than that after rabeprazole alone $(3.45 \pm 1.33$, $\mathrm{P}=0.0376)$. However, there was no significant difference in the median 6-h $\mathrm{pH}$ for rabeprazole plus mosapride $3.81 \pm 0.98$ versus rabeprazole alone $(\mathrm{P}=0.0927)$, or versus rabeprazole administered $1 \mathrm{~h}$ after mosapride $(\mathrm{P}=0.116)$ (Fig. 1).

The intragastric median $\mathrm{pH}$ following the administration of rabeprazole $1 \mathrm{~h}$ after mosapride was higher than that following rabeprazole alone during the 0 - to $4-, 0$ - to 5 - and 0 - to $6-\mathrm{h}$ intervals $(4.35 \pm 0.83$ vs. $3.30 \pm 0.78, \mathrm{P}=0.0284 ; 4.37 \pm 1.07$ vs. $3.47 \pm 0.89, \mathrm{P}=0.0393 ; 4.41 \pm 1.22$ vs. $3.45 \pm 1.33, \mathrm{P}=0.0376$, respectively). There was no significant difference for the 0 - to 1 -, 0 - to 2-, and 0- to 3-h intervals. No significant differences were observed between the average $\mathrm{pH}$ following the administration of rabeprazole plus mosapride and the administration of rabeprazole alone during the 0 - to 1-, 0 - to 2-, 0 - to 3-, 0 - to 4-, 0 - to 5 - and 0 - to 6 -h study periods. Nor were any significant differences observed between the average $\mathrm{pH}$ following the administration of rabeprazole plus mosapride and rabeprazole $1 \mathrm{~h}$ after mosapride during the 0 - to 1 -, 0 - to 2-, 0 - to 3-, 0 - to 4-, 0 - to 5- and 0- to 6-h intervals (Fig. 2). 


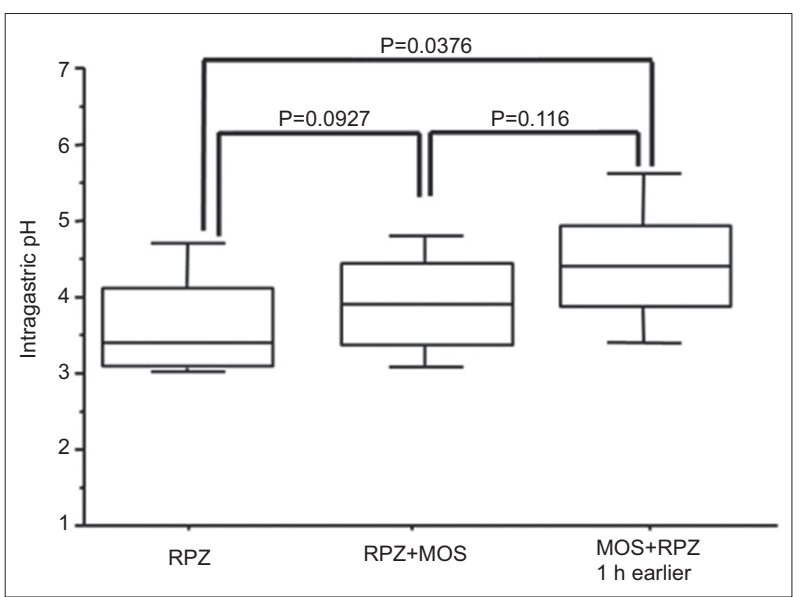

Figure 1 The average $\mathrm{pH}$ during the first $6 \mathrm{~h}$ was higher following the administration of $20 \mathrm{mg}$ rabeprazole $1 \mathrm{~h}$ after the administration of $5 \mathrm{mg}$ mosapride than following $20 \mathrm{mg}$ rabeprazole alone ${ }^{\star} \mathrm{P}=0.0376$ by the Wilcoxon signed-rank test RPZ, Rabeprazole; MOS, Mosapride

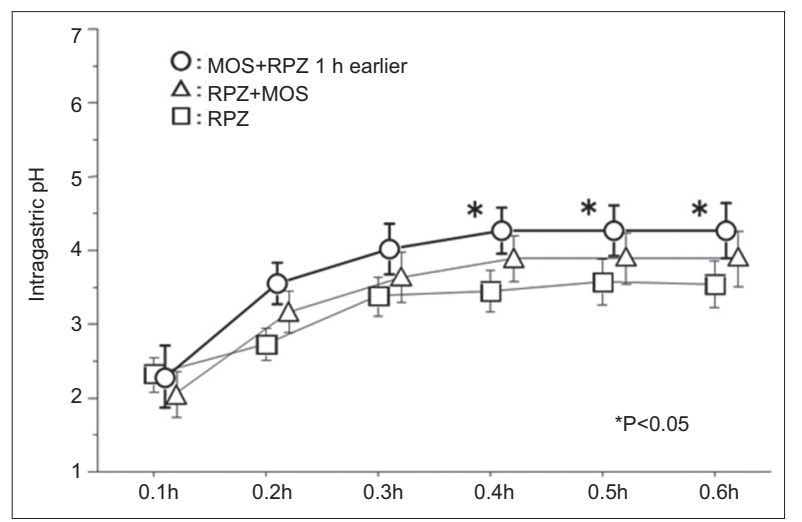

Figure 2 Administration of $20 \mathrm{mg}$ rabeprazole $1 \mathrm{~h}$ after $5 \mathrm{mg}$ mosapride resulted in a higher average $\mathrm{pH}$ compared to $20 \mathrm{mg}$ rabeprazole alone in the 0 - to 4-, 0 - to 5- and 0- to 6-h study periods following administration. Squares (20 mg rabeprazole administered $1 \mathrm{~h}$ after $5 \mathrm{mg}$ mosapride), triangles ( $20 \mathrm{mg}$ rabeprazole with $5 \mathrm{mg}$ mosapride) and circles (20 $\mathrm{mg}$ rabeprazole), mean values; vertical lines, standard deviations (SD); horizontal lines, $\pm \mathrm{SD}$

${ }^{*} \mathrm{P}=0.0284,0.0393$ and 0.0343 by the Wilcoxon signed-rank RPZ, Rabeprazole; MOS, Mosapride

During the 6-h study, the administration of rabeprazole $1 \mathrm{~h}$ after mosapride provided longer durations of $\mathrm{pH}>3.5,4,5$ and 6 compared with rabeprazole alone (median: $56.4 \pm 8.64 \%$ vs. $36.8 \pm 9.98 \%, \quad \mathrm{P}=0.0461 ; 51.6 \pm 8.64 \%$ vs. $29.9 \% \pm 6.74$, $\mathrm{P}=0.0412 ; 42.5 \pm 6.85 \%$ vs. $19.6 \pm 3.11 \%, \mathrm{P}=0.0347 ; 38.6 \pm 5.36 \%$ vs. $12.8 \pm 2.89 \%, \mathrm{P}=0.0449$, respectively). No such significant differences were observed between the $\mathrm{pH}$ durations after the administration of rabeprazole plus mosapride and those after the administration of rabeprazole alone. Nor was any such significant difference seen between the $\mathrm{pH}$ durations following the administration of rabeprazole with mosapride and rabeprazole $1 \mathrm{~h}$ after mosapride (Fig. 3).

\section{CYP2C19 genotype}

CYP2C19 has the following alleles: wild-type, CYP2C19*1, CYP2C19*2 (G681A in exon 5), and CYP2C19*3 (G636A in exon 4 ). The volunteers were classified into three genotype groups by the presence of $\mathrm{m} 1$ and $\mathrm{m} 2$ : extensive metabolizer (EM: CYP2C19*1/*1), intermediate metabolizer (IM: CYP $2 C 19^{\star} 1{ }^{*} 2$ and ${ }^{*} 1 /{ }^{*}$ ), and poor metabolizer (PM: CYP 2 C $\left.199^{*} 2{ }^{*} 2,{ }^{*} 2 /{ }^{*} 3,{ }^{*} 3 /{ }^{*}\right)$.

CYP2C19 is a major enzyme related to the metabolism of PPIs. Therefore, differences in the plasma concentration of PPI are observed among CYP2C19 genotypes and the degree of inhibition of acid secretion is influenced by these differences. In this study, 4 subjects were genotyped as EM, 5 subjects were IM and the other 3 subjects were PM (Table 1). No significant differences among EM, IM, and PM were observed with regard to $\mathrm{pH}$ or $\mathrm{pH}$ holding time.

\section{Discussion}

In this study, we examined intragastric $\mathrm{pH}$ transition during the early post-administration phase after a single oral administration of rabeprazole alone, rabeprazole plus mosapride, and rabeprazole administered $1 \mathrm{~h}$ after mosapride in H. pylori-negative volunteers. The intragastric $\mathrm{pH}$ in H. pylori-positive subjects is higher than that in $H$. pylorinegative volunteers, because gastric acid decreases in $H$. pyloripositive subjects. Hence, we chose $H$. pylori-negative volunteers for this study.

Mosapride is a novel gastrokinetic agent that enhances gastrointestinal motility by stimulating the serotonin receptor. In conscious dogs, mosapride enhances upper gastrointestinal motor activity in the postprandial state [14]. After oral administration in rats, mosapride is absorbed in the small intestine [15].

In healthy adults, mosapride accelerates gastric emptying [16]. This study suggests that mosapride might accelerate rabeprazole absorption in the small intestine by accelerating gastric emptying. For example, capsule endoscopy has demonstrated that mosapride speeds up gastric emptying and increases the completion rates of a small bowel examination in patients [17]. In the mosapride group, the gastric emptying time was decreased, suggesting that mosapride shortens the gastric emptying time. We often use mosapride with oral intestinal lavage solution, polyethylene glycol-electrolyte lavage solution (PEG-ELS) as preparation for a barium enema examination. PEG-ELS with mosapride is more effective than PEG-ELS alone (the modified Brown's method), commonly used in Japan [18]. Moreover, mosapride reduces gastric emptying time and gastroesophageal reflux by improving gastrointestinal motility [19]. Mosapride influences the pharmacokinetics of rabeprazole. The use of mosapride resulted in significant increases in the mean $\mathrm{C}(\max )$ and mean area under the curve of rabeprazole [20]. 
There are multiple factors related to the exacerbation of GERD. Acid reflux from the stomach to the esophagus is understood as the major reason for GERD. PPIs have a potent, long-term ability to suppress gastric acid, so PPIs are essential medicine for GERD [21] management. In contrast, the shortterm, temporary gastric acid reflux is mainly attributed to the mild GERD transient heartburn. Water and H2RAs increase the intragastric $\mathrm{pH}$ immediately, whereas PPIs increase it slowly [22]. However, PPIs have a more prolonged effect than H2RAs [3]. Consequently, for the resolution of heartburn symptoms, the rapid suppression of gastric acid secretion is one of the most important factors [23]. Because omeprazole with mosapride increases the intragastric $\mathrm{pH}$ immediately [10], it was naturally recognized as a useful on-demand therapy for

Table 1 Patient characteristics of CYP2C19 genotype

\begin{tabular}{lcccll} 
No & Age & Height & Weight & CYP2C19 & H. pylori \\
\hline 1 & 35 & 179 & 70 & EM & Negative \\
2 & 27 & 170 & 80 & IM & Negative \\
3 & 20 & 175 & 60 & IM & Negative \\
4 & 21 & 173 & 58 & EM & Negative \\
\hline 5 & 22 & 180 & 75 & PM & Negative \\
6 & 20 & 168 & 63 & PM & Negative \\
\hline 7 & 22 & 175 & 73 & EM & Negative \\
8 & 24 & 175 & 69 & EM & Negative \\
\hline 9 & 20 & 169 & 59 & IM & Negative \\
10 & 21 & 175 & 88 & IM & Negative \\
11 & 26 & 182 & 73 & PM & Negative \\
12 & 20 & 174 & 68 & IM & Negative \\
\hline
\end{tabular}

H. pylori, Helicobacter pylori

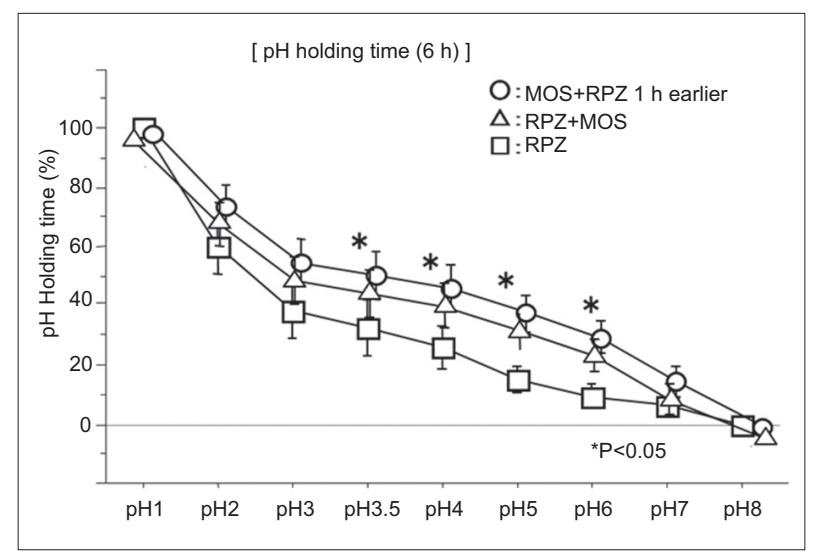

Figure 3 During the 6-h study period, $20 \mathrm{mg}$ rabeprazole administered $1 \mathrm{~h}$ after $5 \mathrm{mg}$ mosapride resulted in longer durations of $\mathrm{pH}>3.5$, 4, 5 and 6 compared to $20 \mathrm{mg}$ rabeprazole alone. Squares $(20 \mathrm{mg}$ rabeprazole administered $1 \mathrm{~h}$ after $5 \mathrm{mg}$ mosapride), triangles (20 $\mathrm{mg}$ rabeprazole with $5 \mathrm{mg}$ mosapride) and circles (20 mg rabeprazole), mean values; vertical lines, standard deviations (SD); horizontal lines, $\pm \mathrm{SD}$

${ }^{*} \mathrm{P}=0.0461,0.0412,0.0347$ and 0.0449 by the Wilcoxon signed-rank test RPZ, Rabeprazole; MOS, Mosapride patients with mild GERD. Rabeprazole with mosapride might accelerate the onset of action; it might be more suitable for on-demand therapy than rabeprazole alone. Moreover, fixed rabeprazole plus mosapride combination therapy might be more useful than rabeprazole alone.

If mosapride accelerates the absorption of rabeprazole that raises the question why was the gastric $\mathrm{pH}$ not higher during the 0 - to $1-, 0$ - to $2-$, or 0 - to 3 -h periods (Fig. 2)? We suspect that mosapride has a less strong and less rapid effect during the earlier phases, otherwise we might have observed an accelerated gastric emptying during the above-mentioned early periods. The Tmax is $0.8 \pm 0.1(\mathrm{~h})$, the $\mathrm{Cmax}$ is $30.7 \pm$ $2.7 \mathrm{ng} / \mathrm{mL}$, and the $\mathrm{T} 1 / 2$ is $2.0 \pm 0.2 \mathrm{~h}$ after oral administration of $5 \mathrm{mg}$ mosapride.

Intragastric $\mathrm{pH}$ did not increase during the 0 - to 4 - and 0 - to 5-h study periods (Fig. 2). What was the reason for this transient lack of increase in intragastric $\mathrm{pH}$ while using a PPI? Because PPIs can block only activated proton pumps, the blood concentration of rabeprazole does not directly reflect intragastric $\mathrm{pH}$. Our previous report showed that, after administration of a PPI, the increase in intragastric $\mathrm{pH}$ value exhibited some up and down fluctuations, whereas after the administration of $\mathrm{H} 2 \mathrm{RA}$, the intragastric $\mathrm{pH}$ value consistently increased [23-25]. This is because, after repeated intravenous or

\section{Summary Box}

\section{What is already known:}

- Oral administration of histamine 2 receptor antagonists (H2RAs) plus mosapride citrate increases the intragastric $\mathrm{pH}$ more rapidly than H2RA alone

- Omeprazole administered $1 \mathrm{~h}$ after mosapride increases the intragastric $\mathrm{pH}$ more rapidly than omeprazole alone

- No study has yet examined whether administration of a proton pump inhibitor (PPI) plus mosapride might also produce a more rapid increase in intragastric $\mathrm{pH}$ than a PPI alone

\section{What the new findings are:}

- The average intragastric $\mathrm{pH}$ of healthy male subjects in the $6 \mathrm{~h}$ following the administration of $20 \mathrm{mg}$ rabeprazole $1 \mathrm{~h}$ after the ingestion of $5 \mathrm{mg}$ mosapride was significantly higher than that after the administration of $20 \mathrm{mg}$ rabeprazole alone

- In contrast, no significant difference in the average $\mathrm{pH}$ was found when rabeprazole was administered simultaneously with mosapride and compared with rabeprazole alone

- Oral administration of $20 \mathrm{mg}$ rabeprazole preceded by $5 \mathrm{mg}$ mosapride tablets might be suitable for the on-demand treatment of patients with mild GERD 
oral administration of PPIs, the antisecretory activity increases progressively and it takes about 5 days to achieve a steady state. Nakamura reported that H2RAs were bound uniformly to parietal cells in the stomach, whereas PPIs only accumulated on young activated parietal cells and other proton pumps were quickly activated. Thus, in the early period after the medicine, we found a slower onset of antisecretory action with PPIs than with H2RAs [26].

Our study has a number of limitations. First, the short (6-h) study term might be insufficient to determine the end effect of both rabeprazole and mosapride on intragastric $\mathrm{pH}$. Second, the data were collected from healthy volunteers and not from GERD patients in whom on-demand therapy might be insufficient. Further studies might be necessary to overcome these limitations.

An ideal medication for acid-related diseases should offer both a rapid action to promote the stopping of blood flow and the efficient achievement of symptom resolution. According to our results, we conclude that rabeprazole administered $1 \mathrm{~h}$ after mosapride produced an increase in intragastric $\mathrm{pH}$ more rapidly than rabeprazole alone in healthy, male, $H$. pylorinegative volunteers. Although the clinical implications of our results are unclear, our findings suggest that oral administration of rabeprazole preceded by mosapride might be suitable for the on-demand treatment of mild GERD. To evaluate the effects on GERD patients, further studies might be necessary.

In conclusion, an oral dose of rabeprazole administered $1 \mathrm{~h}$ after mosapride increased the intragastric $\mathrm{pH}$ more rapidly than rabeprazole alone in healthy, male, H. pylori-negative volunteers.

\section{Acknowledgments}

Special thanks to the medical staff of the Gastroenterology Division, Yokohama City University Hospital, Kanagawa, Japan.

\section{References}

1. Graham DY. Critical effect of Helicobacter pylori infection on the effectiveness of omeprazole for prevention of gastric or duodenal ulcers among chronic NSAID users. Helicobacter 2002;7:1-8.

2. Frazzoni M, De Micheli E, Grisendi A, Savarino V. Effective intraoesophageal acid suppression in patients with gastro-oesophageal reflux disease: lansoprazole vs. pantoprazole. Aliment Pharmacol Ther 2003;17:235-241.

3. Robinson M. Proton pump inhibitors: update on their role in acidrelated gastrointestinal diseases. Int J Clin Pract 2005;59:709-715.

4. Malfertheiner P, Mössner J, Fischbach W, et al. Helicobacter pylori eradication is beneficial in the treatment of functional dyspepsia. Aliment Pharmacol Ther 2003;18:615-625.

5. Fass R, Shapiro M, Dekel R, Sewell J. Systematic review: protonpump inhibitor failure in gastro-oesophageal reflux diseasewhere next? Aliment Pharmacol Ther 2005;22:79-94.

6. Bardhan KD. Intermittent and on-demand use of proton pump inhibitors in the management of symptomatic gastroesophageal reflux disease. Am J Gastroenterol 2003;98(3 Suppl):S40-S48.

7. Ofmann JJ. The economic and quality-of-life impact of symptomatic gastroesophageal reflux disease. Am J Gastroenterol 2003;98:S8-S14.

8. Burget DW, Chiverton SG, Hunt RH. Is there an optimal degree of acid suppression for healing of duodenal ulcers? A model of the relationship between ulcer healing and acid suppression. Gastroenterology 1990;99:345-351.

9. Iida $\mathrm{H}$, Inamori M, Nozaki Y, et al. Early effects of oral administration of lafutidine with mosapride compared with lafutidine alone on intragastric $\mathrm{pH}$ values. BMC Gastroenterol 2009;9:52.

10. Iida $\mathrm{H}$, Inamori $\mathrm{M}$, Fujii $\mathrm{T}$, et al. Early effect of oral administration of omeprazole with mosapride as compared with those of omeprazole alone on the intragastric pH. BMC Gastroenterol 2012;12:25.

11. Kubota T, Chiba K, Ishizaki T. Genotyping of S-mephenytoin 4'-hydroxylation in an extended Japanese population. Clin Pharmacol Ther 1996;60:661-666.

12. de Morais SM, Wilkinson GR, Blaisdell J, Nakamura K, Meyer UA, Goldstein JA. The major genetic defect responsible for the polymorphism of S-mephenytoin metabolism in humans. J Biol Chem 1994;269:15419-15422.

13. De Morais SM, Wilkinson GR, Blaisdell J, Meyer UA, Nakamura K, Goldstein JA. Identification of a new genetic defect responsible for the polymorphism of (S)-mephenytoin metabolism in Japanese. Mol Pharmacol 1994;46:594-598.

14. Yoshikawa T, Yoshida N, Mine Y, Hosoki K. Affinity of mosapride citrate, a new gastroprokinetic agent, for 5-HT4 receptors in guinea pig ileum. Jpn J Pharmacol 1998;77:53-59.

15. Yoshida N, Ito T, Karasawa T, Itoh Z. AS-4370, a new gastrokinetic agent, enhances upper gastrointestinal motor activity in conscious dogs. J Pharmacol Exp Ther 1991;257:781-787.

16. Kanaizumi T, Nakano H, Matsui Y, et al. Prokinetic effect of AS-4370 on gastric emptying in healthy adults. Eur J Clin Pharmacol 1991;41:335-337.

17. Wei W, Ge ZZ, Lu H, Gao YJ, Hu YB, Xiao SD. Effect of mosapride on gastrointestinal transit time and diagnostic yield of capsule endoscopy. J Gastroenterol Hepatol 2007;22:1605-1608.

18. Futei S, Sugino Y, Kuribayashi S, et al. New preparation method for barium enema: efficacy and administration of oral intestinal lavage solution with gastrointestinal prokinetic agent. Nihon Igaku Hoshasen Gakkai Zasshi 2004;64:22-30.

19. Yoshida N, Omoya H, Oka M, Furukawa K, Ito T, Karasawa T. AS-4370, a novel gastrokinetic agent free of dopamine D2 receptor antagonist properties. Arch Int Pharmacodyn Ther 1989;300:51-67.

20. Arai K, Takeuchi Y, Watanabe H, Tsukurimichi A, Uchida N, Imawari M. Prokinetics influence the pharmacokinetics of rabeprazole. Digestion 2008;78:67-71.

21. Ruth M, Hamelin B, Röhss K, Lundell L. The effect of mosapride, a novel prokinetic, on acid reflux variables in patients with gastrooesophageal reflux disease. Aliment Pharmacol Ther 1998;12:35-40.

22. Karamanolis G, Theofanidou I, Yiasemidou M, Giannoulis E, Triantafyllou K, Ladas SD. A glass of water immediately increases gastric $\mathrm{pH}$ in healthy subjects. Dig Dis Sci 2008;53:3128-3132.

23. Inamori M, Togawa J, Iwasaki $\mathrm{T}$, et al. Early effects of lafutidine or rabeprazole on intragastric acidity: which drug is more suitable for on-demand use? J Gastroenterol 2005;40:453-458.

24. Abe $\mathrm{Y}$, Inamori M, Togawa J, et al. The comparative effects of single intravenous doses of omeprazole and famotidine on intragastric pH. J Gastroenterol 2004;39:21-25.

25. Inamori M, Togawa J, Chiguchi G, et al. Evaluation of the effects of anti-secretory drugs on intragastric acidity: is combined therapy with a proton pump inhibitor and an $\mathrm{H} 2$ receptor antagonist effective as initial treatment? J Gastroenterol 2005;40:213-214.

26. Nakamura M, Oda M, Akiba Y, et al. Autoradiographic demonstration of lansoprazole uptake sites in rat antrum and colon. J Clin Gastroenterol 1995;20(Suppl 2):S8-S13. 